\title{
$\vdots$ \\ A DIAGNOSTTC HIERARCHY APPROACH TO \\ ROOT CAUSE ANALYSIS \\ FOR HEAVY WATER REACTOR MALFUNCTION MANAGEMENT
}

Final Report

by

Don W. Miller, Brian K. Hajek and J. Wesley Hines

Nuclear Engineering Program

Department of Mechanical Enginêting

The Ohio State University

Columbus, Ohio 43210

October 30, 1993 


\section{DISCLAIMER}

This report was prepared as an account of work sponsored by an agency of the United States Government. Neither the United States Government nor any agency thereof, nor any of their employees, make any warranty, express or implied, or assumes any legal liability or responsibility for the accuracy, completeness, or usefulness of any information, apparatus, product, or process disclosed, or represents that its use would not infringe privately owned rights. Reference herein to any specific commercial product, process, or service by trade name, trademark, manufacturer, or otherwise does not necessarily constitute or imply its endorsement, recommendation, or favoring by the United States Government or any agency thereof. The views and opinions of authors expressed herein do not necessarily state or reflect those of the United States Government or any agency thereof. 


\section{DISCLAIMER}

Portions of this document may be illegible in electronic image products. Images are produced from the best available original document. 


\section{TABLE OF CONTENTS}

\subsection{INTRODUCTION}

\subsection{Background}

1.2 Discussion of Goals and Objectives

\subsection{PROGRESS IN ACHIEVING GOALS AND OBJECTIVES}

2.1 Verification and Validation Plan

2.2 Heavy Water Reactor Plant Description

2.3 Diagnostic Systetn Architecture

2.4 Knowledge Acquisition

2.5 Knowledge Representation

2.6 Testing and Resuls

3.0 SUMMARY

4.0 EDUCATIONAL ACHIEVEMENTS

5.0 REFERENCES

6.0 APPENDIX

6.1 V\&V Documents

6.2 Master's Theses Abstracts

6.3 Ph.D. Dissertation Abstruets

6.4 Published Papers 


\subsection{INTRODUCTION *}

This repor summarizes the research accomplished made under the Deparment of Energy Office of Energy Research Special Research Grant Program in Nuclear Engineering through the DOE-ER Nuclear Engineering Education Research Program grant number DE. FG07-90ER 13028.

In Chapter 1, we present an introduction and background materjal for the operator advisor research undergoing at The Ohio State University. We then discuss the original project goals and explain why they changed throughout the project.

In Chapter 2, we outline our methodology for achieving the proposed goals and describe the verification and validation program that we used to guide our project development. The original diagnostic systerm architecture is presented along with the changes that we have implemented. Next, a discussion of knowledge acquisition and knowledge representation is given; and lastly, we will describe the testing that was performed and present their results.

In Chapter 3, we list the educational benefits that resulted though this project and give a brief description of the technical papers and resulting master thesis.

\subsection{Background}

In February of 1990 a proposal was submitted to investigate designing a diagnostic operator aid for the heavy water reactors at the Savannah River Site (SRS). At that time the Scientific Computations Section (SCS) at the SRS was designing an Intclligent Reactor Information System (IRIS). The faculty and students in the Nuclear Engineering Artificial Intelligence (AD) Group at The Ohio State University (OSU) had been developing an Operator Advisor (OA) for the Perry Nuclear Power Plant using a diagnostic hierarchy approach [1,2]. The original proposal outlined a joint effort between the Nuclear Engineering AI Group and the Chemicnl Engineering AI Group at OSU to design and integrate a heavy water reactor version of this diagnostic system into IRIS. It was expected that this integrated AI based information system would be included in the design of the New Production Reactor. Following initiation of this research, the New Production Reactor was canceled and IRIS was put on hold.

In response to the changing needs at Savannah River, we modified our original objective of designing a system to merge with IRIS to that of developing a "stand alone" version of the diagnostic expert system for the Heavy Water Reactor (HWR) facilities located at the Savannah River Site (SRS). The emphasis on this new objective was to complete a "Text Book" design, development and evaluation of this system. Since software is increasingly being used to perform various tasks at nuclear power plants and for other applications where safety is a crilical issue, there is an effor to specify the design and testing requirements for this safety critical software. ANSI-IBEE has developed several standards to use for guidelines $[3,4,5,6]$ and EPRI has published several reports to assist in developing expert system software [7,8]. The new gnal was to use these standards and reports to design an expert system and to document the design and devclopment to provide guidance for future design projects.

The purpose of the expert system was to assist the human operator in effectively maintaining plant safety and to enhance plant reliability. Although the design changed to that of a stand alone unit, it still used a hievarchy based diagnostic architecture similar to that of the Operator Advisor. 


\subsection{Discussion of Goals and Objectives}

Although the plans to integrate the diagnostic system into IRIS werc canceled, several of the initial goals remained, First, in conjunction with SRS personnel the researth plan wes refined. Nexh plant specific knowledge was axquired through close interaction with SRS personnel One or two systems were then selected for further.analysis, these systems were decomposed into a diagnostic hierarchy, and scenarios were selected to test the system. These goals are summarized into the groups of knowledge acquisition, knowledge representation, and knowiedge testing. These three objectives art discussed in depth in the next chapter, along with the methodology used to efficiently condues the specific tasks.

\subsection{PROGRESS IN ACHIEVING GOALS AND OBJECTIVES}

\subsection{Verification and Validation Plan}

Many expert systems, including the OSU Opentor Advisor, are built through a rapid prototyping process. Through this process, no formal Sofrware Verification and Validation Plan (SVVP) or Software Requirements Specification (SRS) is doveloped prior to initial prototyping. This rapid prototyping method gives little or no guidance to the developer in the form of what the software reguirements are and how to confirm that the system meets those requirements. I also provides litte documented evidence of the ability of the end design to meet any functional requirements. This audit trail is of vital impontance in licensing safety critical software. Because of these drawbacks to rapid prototyping. we developed a standardized approsch to Verification and Validation (V\&V) that we would implement in our "text book" desigh and development. Wc used this approach to guide the system development through the desiga phases and to ensure that the end product fulfilled the initial requirtments and project ofjectives.

The basic function of a V\&V program is so ensure the production of a quality software product that is crrot free and that functions as desired. It performs this, function by evaluating the software product at specified stages, from its initial concept coifts installation and operation. It verifies the soltware product at the end of ench stage to ensure terror free operation (internal correctness), and it yalidates the software product at the end of the software development to ensure the final product incorporates both the fenures and functionality as prescribed by the sofiware requirement specifications (exicmal comectness) and 'most importantly, meets the needs of the user.

Wo intrgrated formal V\&V procedures with the developrent of the software produch to tealize the following benefits:

L. Earlier and less costly error detection.

2. Improved tracking of the software development by management.

3. Figher software quality and reliability.

4. Beiter system maintainability.

5. A well defined end prodect that better meets the initial objectives.

6. A more structured and focused development environment resulting it more cfincient development.

The IEEE Standard for Software Verification and Validation Plans (SVVPS) was used to construct the SVVP for the ncw system. This plan oulines the V\&V tasks necessary to verify the product at the end of each software life-cycle phase, and to validate that the end product complies with the establihhed software and system requirements [3]. The IEEE Guide to

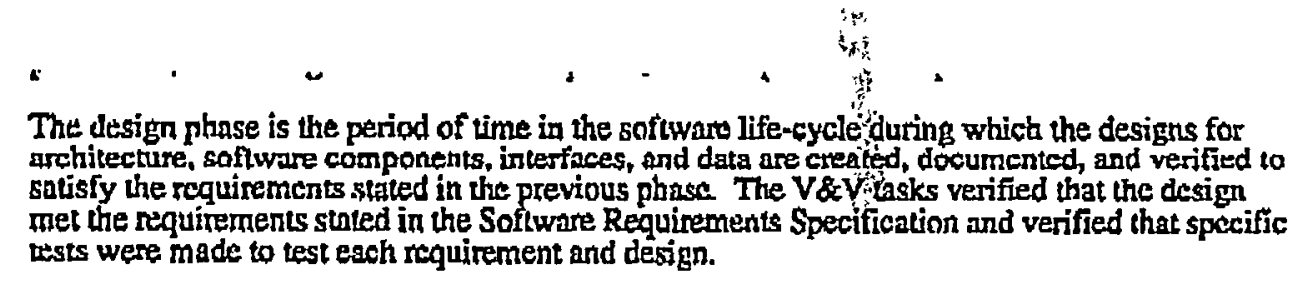


The expert system for HWR diagnosis is composed of six distinct design entivies that reside on a SUN IPC SPARCstation as shown in Figure 3. The data link communicates data requests to a data server, and receives data from the data server as required for the operation of the expert system. On site at SRS, the data-server is a Symbolics 3645 LISP machine interfaced with the Gould simulator via a high speed parallel data bus link. The SUN IPC communicates its data requests over an ethernet to the Symbolics through remote procedure calls, and receives data packets as requested. At OSU, a SUN SPARCstation 330 emulates the Symbolics machine and serves the data réguests from precollected data files. Using this emulation setup, a proper malfunction data set is chosen and the same remote procedure call is used by the IPC to access the data, over a similar ethernet. This arrangement makes the data server transparent to the diagniostic system; the diagnostic system does not know if it is being served by the simulator or if it is being served from a precollected data file residing on the SUN 330.

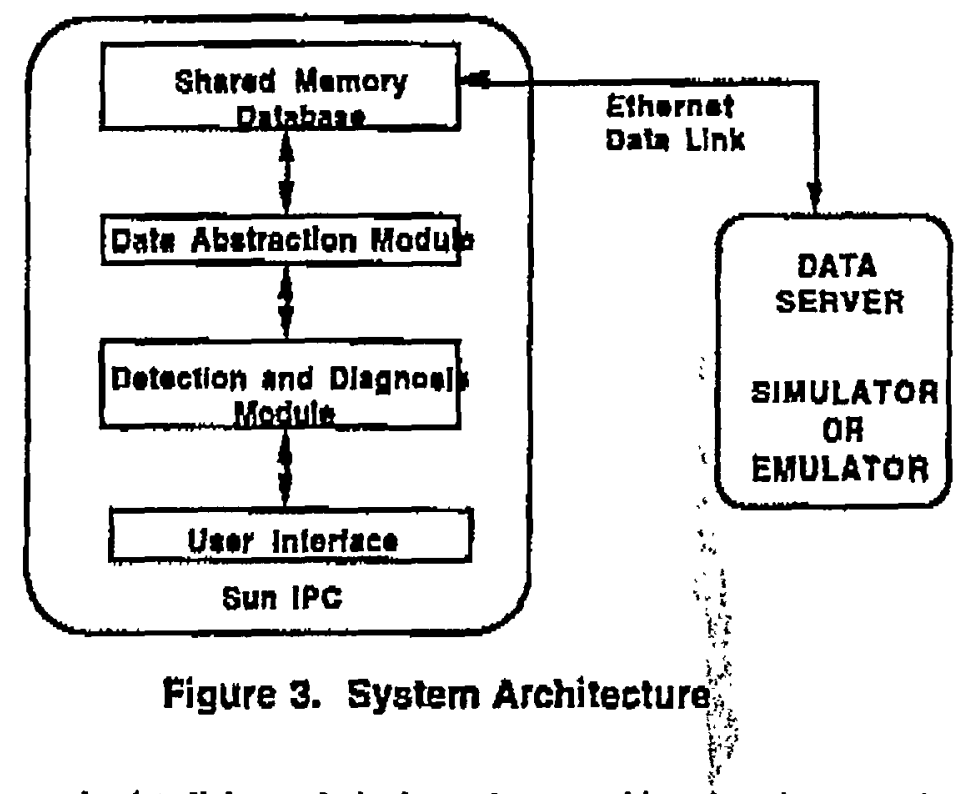

Data is transferred over the data link at a desired sample rate and is wrilten into a section of memory called shared memory. This memory seganent is accessible by other processes and is the fastest means of internal process communication on the SUN, This high-speed dalabase is used to store the data for later retrieval. The data is time stamped with the actual simulation time which is transierred across the data link with the data pack. The data is saved for a specified time period. This results in the ability to access the complete history of parameter variations for use in detecting deviations from nomality and for use in diagnosing the deviation.

The basic function of the data abstraction module is to convert raw dala into a more usable form. It does this by accessing raw dala from the database, performing functions on this taw data, and then retuning the result to the monitoring or diagnostic modules. This module is actually composed of many smailer modules that perform computations such as trend analysis, and limit cbecking. The results can be quantitative, such as 5 [degrees/minute], or qualitative, such as quickly increasing. Examples are: the number of running pumps, alarm status, heat up rates, and valve positions.

The basic function of the monitoting module is to monitor certain critical plant paramelers and identify abnomal changes. It performs this function hy first querying the shared memory datahase for prestefined plant parameters and then comparing them to gredefined limits. This inonitoring process is continuous while at power and only stops if a deviation is delected and diagnosis bass been initizted.

The basic funclion of the diagnostic module is to find the root cause of any deviation from normality. First it receives an initiation message from the monitoring module, then it prines the search space using an 
We interviewed reactor opemtors, texctor training persontel, and reactor engineers to determine both the plant response and the operator response to simulated Process Water malfunctions. We participated in malfunction walk-throughs at the full function simulator and observed reator opertor crews manage the malfunctions. We documented the indicators that were consulted, the seguence of actions taken, and the resulis of those actions. This documentration provided us with a detailed list of the key indications and parameter variations that occur during the simulated malfunctions.

Nexh we ran malfunction scenarios on the engineering simulator and complied a list of plant parameter trend varistions. We expanded the orginal list to include all parameters that varied, even if they were not used by the operators to perform diagnosis. To vbtain a hard copy of the reactor parameter variations, we connected a data link between the engineering simulator and a SUN IPC SPARCstation. Over two hundred and fifty data points were transferted every second over an ethemet and written to a data file. :

We collected a tive minute data file for each malfunction scephrio, graphed the plant parameters, and analyzed them to determine expected and unexpected trends. The anglysis of these trends combined with the diagnostic methodologies employed by the operators provide the basis for the hierarchy construction. We also saved the data files to disk to be used at OSU to emulate the data transfer of the simulator, this simulntor emulation will be explained later.

\subsection{Knowledge Reptesentation}

After gathering knowledge on bow the system and the operators respond to malfunctions, the knowledge was organized into a malfunction hypothesis hierarchy. In this hicrarthy. the top nodes represent more general malfunction hypotheses while the lower levels correspond to more specific maliunction hypotheses. The bottom level nodes, called lip nodes. map to the root cause of the malfunction.

The hierarchy is taversed in a top down fashion with an establish-refine methodology. Knowledge is represented in the hietarchy with data groups thet are attached to the malfunction hypothesis nodes. These knowledge grouns represent patterns of data that either establish or reject the malfunction hypothesis at a specific node. A malfunction node is established if the plant data matches the pre enumerated patlem that identifies that malfunction. If a malfunction node is established, its children nodes are examined to sefine the hypothesis. If a malfunction node is nol establisted, then its children nodes are noled out alsn. This methodology prunes the search space by ruling out entire hranches of the hypothesis space, thus speeding the dingnostic process.

The tool originally chosen to implement this control strategy is CSRL (Conceptual Structures Representation Language). CSRL was developed by The Ohio State University Laboratory of Artificial Intelligence Resennch (LAIR) in 1983 ito be used for classilicatory problem soiving [2]. It is a LISP-based tool, bul calls C functions to access the plant data, CSRL was replaced with a similar cool written in $\mathrm{CH}$. The system was upgraded to $\mathrm{C}++$ for the following reasons:

1. CSRL had a compilation time of 20 to 30 minutes for knowledge groups as large as ours. This meant that cvery time a change was made to a knowledge group, the entire hierarchy was secompiled creating a 20 to 30 minute delay. With $\mathrm{C}++$ this delay was reduced to about 30 seconds.

Figure 5. Functional Based Decompositlon 
would determine if the system actually helps the operators detect and diagnose process water malfunctions. This testing was mate impossible due to the unavailahitity of the full function simulator and the lack of barlware and software necessary to hook up the data link.

\subsection{SUMMARY}

The Nuclear Engineering and Chemical Engineering Artificial Intelligence Groups at The Ohio State University have developed a diagnostic system for the heavy water production reactors at the Savannah River Site.

The diagnostic module of the system uses hybrid hierarchical decomposition raethodology to decompose the search space. The knowledge is arranged so that the search space is traversed similarly to how an expert would solve the problem. The system was tested on the SRS development simulator and the results show that the system can properly diagnose all the process water and cooling water malfunctions that are programmed into the simulator. The system was not validated by operators duefto hardware unavailability. Since the New Production Reactor development efforts have becn balted, the probability for future work on this project is unlikely.

The development used a standardized Verification and Validation program to assist in the design and construction of the system. The use of this standardized procedure is referred to as a "text book" example of designing an expert system in the expectation that its use would provide guidance in future projects.

Of the eight phases of the software development lifecycle, five of the phases were completed and documented. The lifecycle began with the concept phase where the user's needs were determined. During the requirements phase the software requirements specification was developed to meet the user's needs and a software test plan was written to test those specifications. The design phase led to the development of a software design description which met the specifications. During the system implementation and testing phase, the components were tested and integrated to form a diagnostic systcra which was also tested. Knowledge was entered and tested in the knowledge representation and testing phase. The validation phase was not performed because of limitations on site as discussed above and the system implementation and testing phase and the operation and maintenance phase were not completed.

Although the system was not validated or installed and used, the standardized approach to the design and development proved useful throughout the development process. It provided guidance and direction to the development team arid provided the management oversight committee with a checklist that was helpful in fulfilling their function. Lastly it provided an audit trail that documented what was completed; what crors were found, how the errors were corrected, what decisions were made and why those decisions were made. This audit trail would be useful to the design of a similar product and it would also be useful for the technical investigations that may be performed by a licensing committee.

One important requirement of a V\&V system that was not implemented was that there was no separation of the design and $V \& V$ personnel. This was due to the limited personnel assigned to the project. Although the management committee who reviewed the V\&V documents was separate, the internal V\&V audits and testing were performed by the same personnel that designed and implemented the diagnostic system. This may have limited the effectiveness of the V\&V effort, but however limited it may have been. the system still proved extremely valuable.

\subsection{EDUCATIONAL ACHIEVEMENTS}


This grant provided research support for several graduate students, and a provided a basis for four Master's of Science degnees in Nuclear Engineering. A brief summary of these thesis are included below.

Wes Hines spent his DOE practicum at the Sevannah River Site working for the Scientific Computations Section in designing and implementing the diagnostic system. He conducted the knowledge acquisition and knowledge representation tasks for the process water portion of the system. He designed and lested the initial system and supervised the V\&V tasks. His masters was earned in Spring 1992.

Martin Hass's thesis titled "A Knowledge Based System for the Diagnosis of Coaling Water System Malfunctions in a DOE Production Reactor" (Autumn 1992) centered on the diagnosis of cooling water malfunctions in the K-Reactor, He used real time simulation data in the development and verification of the diagnostic system.

Lane Robbin's thesis titled "An Object Oriented Implementation of a Knowledge-Based System Designed to Diagnose Malfunctions in a Heavy Witter Reactor" (Autumn 1992) was concerned with the conversion of the original LISP hased system to a $\mathrm{C}++$ based system. The new expert system design implemented in $\mathrm{CH}+$ is composed of three main components: a knowledge base, an inference engine, and user interface facilities. An inference engine which takes advantage of the class structure provided in $\mathrm{C}++$ was designed to traverse the hierarchy. A uscr interface facility was designed to display the online monitoring window as well as a message window which displays the results of the diagnosis when an abnormality is detected. Finally, the system was tested through the use of a plant simulator. This testing indicated that all of the simulated malfunctions available could be detected and diagnosed with this system design. This system design also has proven to offer many advantageous over the LISP-based system. It is fully functional with the Unix Operating System and the X-Window system which allows for direct correspandence with system calls and library subroutines. The compilation time is on the order of seconds as opposed to 15 - 20 minutes for the LISP-based system. Thus the new system was proven to be much more maintainable.

Satord Kiyohashi's thesis titled "An improved Implementation of a Knowledge Based System for the Diagnosis of Malfunction in a Commercial Boiling Water Reactor" (Spring 1993) expanded on the system improvements made by Lane Robbins. Although he used a boiling water reactor as the reference plant, the improvements were made available to the SRS system. The improvements included a better user interface with browsers, a high modularity of programs, a complete separation of the knowledge base from the inference engine and other routines, and the capability to handle multiple malfunctions.

In addition to these four Nuclear Engineering master's theses, this research also contributed to two Chemical Enginearing Ph.D. dissertnlions: James K McDowell's dissertation was titled "The Integration of Mndel-Based Reasoning and Task Specific Problem-Solving Architectures for Chemical Process Diagnosis" (1991), and Prasad Ramanathan's dissertation was titled "Diagnostic Knowledge-Based Systems for Continuous Chemical Processes: Enhanced Knowledge Acquisition \& Generic Problem-Solving Framework" (1993).

Several technical papers were presented at technical conferences and published in the their respective proceedings $[11,12]$. Copies of these papers are included as Appendix 6.3. 


\subsection{REFERENCES}

1. Bhatnagar R., Miller D. W., Hajek B. K., Stasenko J. E., "An Integrated Operator Advisor System for Plant Monitoring, Procedure Management, and Diagnosis", Nuclear Technology Mar. 1990: 281-317.

2. Bylander, T., Mittal, S., Chandrasekaran, B., "CSRL A Language for Expert Systems for Diagnosis", Proceedings of the International Joint Conference on Artificial Intelligence, William Kaufman, Inc, Los Altos, CA., Aug. 1983, pp 218-221.

3. ANSI/IEEE Std 1012-1986, IEEE Standard for Software Verification and Validation Plans.

4. ANSI/IEEE Std 830-1984, IEEE Guide to Software Requirements Specification.

5. ANSI/IEEE Std 1016-1987, IEEE Recommended Practice for Software Design Descriptions.

6. ANSI/LEEE Std 829-1983, IEEE Standard for Software Test Documentation.

7. Kirk, D. B., Murray, A. E., "Verification and Validation of Exper Systems for Nuclear Power Plant Applications", EPRI NP-5978, Aug: 1988.

8. Groundwater, E. H., Kirk, D. B., Murray, A. E., "Thë्EPRI Knowledge Acquisition Workshop Handbook", EPRI NP-6240, Feh. 1989.

9. Hoecker, D. G., Pople, H. E., Benhardh, H. C., "Initiẩ̆ Simulation at Savannah River", Westinghouse Science and Technology Center Report 909\$24-SACES-R1, May, 1991.

10. Hardy, C. R., Ha, J., Hajek, B. K., Miller, D. W., "A Real Time Expert System for the Detection and Diagnosis of Abnomal Conditions in Nuclear Power Plants", Proceeding of Al91: Frontiers in Innovative Computing for the Nuclear Industry, sponsored by the American Nuclear Society, Jackson, Wyoming, Sept. 15-18, 1991.

11. Hines, J.W., D. W. Miller, B. K. Hajek, "A Standardized Approach to Verification and Validation to Assist in Expert Systern Development", presented and published in the proceedings of the of the 8th Power Plant Dyanmics Control \& Testing Symposium, Knoxville, TN., May 27-29, 1992.

12. Hines. J. W., D. W. Miller, B. K. Hajek, "A Hierarchical Paradigm for Root Cause Analysis of Process Water Malfunctions in a Heavy Water Reactor Facility". presented and published in the proceedings of the 8th Power Plant Dyanmics Control \& Testing Symposium. Knoxville, TN., May 27-29, 1992. 


\subsection{APPENDIX}

\subsection{V\&VDocuments \\ Software Verification and Validation Plan}

Software Requirements Specification and Design pescription

Software Test Plan

6.2 Master's Theses .

Martin Hass's thesis abstract titled "A Knowledge:Based System for the Diagnosis of Cooling Water Systerm Malfunctions in a DOE Production Reactor"

Lane Robbin's thesis abstract titled "An Object Oriented Implementation of a Knowledge-Based System Designed to Diagnose Malfunctions in a Heavy Water Reactor"

Satoru Kiyohashi's thesis abstract tilled "An improved Implementation of a Knowledge Based Systern for the Dingnosis of Malfunction in a Commercial Boiling Water Reactor"

\subsection{PhD Dissertations}

James K. MCDowell's dissertation abstract titled "The Integration of Model-Based Reasoning and Task Specific Problem-Solving Architectures for Chemicnl Process Diagnosis"

Prasad Ramanathan's oissertation abstract titled "Diagnostic Knowledge-Based Systems for Continuous Chemical Processes: Enhanced Knowledge Acquisition \& Generic Problem-Solving Framework"

\subsection{Published Papers}

1. J.W. Hines, B.K. Hajek, D.W. Miller and M.A. Haas; "A Standardized Approach to Verification and Validation to Assist in Expcrt System Deyclopment". Presented and published in the proceedings of the EPRI Conference of Methodologies, Tools, and Standards for Cost Effective, Reliable Software Verification and Validation, Chicago, IL, August 1991 and EPRI Conference on Expert System Applications for the Electric Power Industry, Boston, MA, September 1991.

2. Hines, J.W., D. W. Miller, B. K. Hajek, "A Standardized Approach to Verification and Validation to Assist in Expert System Development", presented and published in the proceedings of the of the 8th Power Plant Dyanmics Control \& Testing Symposium, Knoxville, TN., May 27-29, 1992.

3. J.W. Hines, B.K. Hajek, D.W. Miller, "A Hierarchical Paradigm For Root Cause Analysis of Process Water Malfunctions in a Heavy Watcr Reactor Facility," published and presented at the 8th Power Plant Dynamics, Control \& Testing Symposium Proceedings, Knoxville, Tennessee, May 29, 1992.

4. D.W, Miller, I.W. Hines, B.K. H ajek, L Kharabil, C.R. Hardy, M.A. Haas, L. Robbins, "Experience with the The Hierarchial Method for Diagnosis of Faults in Nuclear Power Plant Systens", Reliability Engineering and Safecy!Systems, 44 (1994), 297-311.

5. J. Wesley Hines, Don W. Miller, B.K Kajek, "A Hybrid Approach for Detecting and Isolating Faults in Nuclear Power Plant Interacting Systems", Nuclear Technology., L15,
343-357, September, 1996. 